\section{EMBRYRIDDLE}

Aeronautical University

SCHOLARLY COMMONS
Journal of Aviation/Aerospace

Education \& Research

Volume 10

Number 1 JAAER Fall 2000

Article 9

Fall 2000

\title{
Voice Recognition in Fighter Aircraft
}

Gary Bell

Marian C. Schultz

mschultz@uwf.edu

James T. Schultz

schul9fd@erau.edu

Follow this and additional works at: https://commons.erau.edu/jaaer

\section{Scholarly Commons Citation}

Bell, G., Schultz, M. C., \& Schultz, J. T. (2000). Voice Recognition in Fighter Aircraft. Journal of Aviation/ Aerospace Education \& Research, 10(1). https://doi.org/10.15394/jaaer.2000.1270

This Article is brought to you for free and open access by the Journals at Scholarly Commons. It has been accepted for inclusion in Journal of Aviation/Aerospace Education \& Research by an authorized administrator of Scholarly Commons. For more information, please contact commons@erau.edu. 


\title{
VOICE RECOGNITION IN FIGHTER AIRCRAFT
}

\author{
Gary Bell, Marian C. Schultz and. James T. Schultz
}

This study explored the significance of the voice type configuration used in U. S. Air Force fighter aircraft voice messaging systems. The research hypothesis stated that the voice of a person in a position of authority is more effective in commanding attention than the generic female voice type currently in use. Data were gathered using a questionnaire presented to U.S. Air Force aircrew members currently flying fighter aircraft. The data were analyzed using a nonparametric Chi-Square test to determine if the voice of a person in a position of authority significantly commands more attention than the female voice. The null hypothesis assumed no difference between the effectiveness of the two voice types. The study found that pilots significantly preferred the current configuration of a female voice. A comparison was also made utilizing a computer-synthesized voice. The results revealed that this computer-synthesized voice is preferred over the voice of an authority figure, but not over the current female voice.

During periods of high task loading, flight members often do not acknowledge or even hear, on a conscious level, auditory inputs. A basic flightlead technique is to recognize when flight members are becoming task saturated by noting when data inputs receive a nonresponse. Discussing a high task flight immediately after landing, or even in the air following the event, a pilot will often deny the assertion that a particular radio call was made, or that an auditory warning system activated. While debriefing with the taped recording of the mission, he or she will be surprised by the clarity of the call or warning, still contending that the call in the air was not heard. What if the call was the voice messaging system alerting the pilot to an incoming threat, or an impending engine problem, or even a potential impact with the ground? Certainly, alerts of this type should be prioritized over almost all other tasks. Unfortunately, the urgency of the message has no impact on whether the message is received by the pilot. He or she simply does not hear it. There is a phenomenon referred to as the "cocktail party effect". In this phenomenon, the subject is able to discern his own name spoken above the ambient noise. While this is not a loudness issue, it is an ability of the mind to filter a piece of information intimately familiar to the subject, when less important information is lost in the clutter of the background noise. If one were to utilize the cocktail party effect to place a higher priority on new data than the tasks at hand, the amount of information the pilot cognitively hears and subsequently is able to process could be increased.

It would be impractical to waste precious seconds prefacing each voice message with the name of the pilot. Perhaps the same effect might be achieved by presenting the voice message in a speaking voice that the pilot immediately recognizes, thereby tricking the mind into believing it was being addressed specifically. Recording the entire vocabulary of the voice messaging system in the speaking voice of someone of significance for each pilot, and then reprogramming the aircraft each time a different pilot flies it would be impractical. Additionally, what benefits would this gain in a two-place aircraft? A possible solution is to use a person in a position of authority for all the potential pilots of a given unit's aircraft, such as the squadron or wing commander. This voice would be easily recognizable and have the possible benefit of having the message taken as an order by the subconscious mind of the pilot.

\section{History}

In the early days of aviation, only rudimentary warning systems were installed on aircraft to aid pilots in recognizing potential hazards. Little more than red markings on the engine instruments and gauges were needed to adequately alert the pilot due to the limited performance of the aircraft. As performance increased, aircraft systems became more complex, and reaction times 
decreased substantially. Clearly, a reliable warning system was needed. With the advent of the first generation tactical fighters, an age of aviation was entered into wherein a single pilot became more of a system manager than strictly a pilot keeping an aircraft away from the ground. Auditory signals began to appear on the more sophisticated aircraft in order to alert pilots to potential and actual problems without overloading the sense of sight. Initially, these auditory warnings were sets of tones designed and differentiated so that they indicated system or urgency by themselves, as well as indicated a need to reference visual indications. Edworthy and Stanton (1995) found that the degree of correspondence between the highest priority situations and warnings is one-to-one. The alarm itself is all the pilot needs to identify the situation. For lower priority situations, the alarm serves as an alerting function, directing the attention of the pilot to a central warning display.

Research later identified two vital elements of aural warning systems. First, that when heard, it is immediately recognized as being a warning. That this is not always the case can be illustrated by this example:

During the approach I was overloaded and received little assistance from the $\mathrm{P} 2$ who made a fast approach. As we flared over the runway a strange noise occurred which I could not identifybut did (fortunately) notice that the gear was still up and a down selection stopped the noise just as we came to the hover. (Edworthy, 1995, p. 2264) The strange noise was, of course, the "GEAR UP" warning tone, though the pilot did not realize this at the time. Second, that the pilot comprehends what the tone represents, and ideally, what actions the pilot needs to take as a consequence (Edworthy, 1995). This realization led to the development of voice messages as warning sounds. Kemmerling, Geiselhart, Thorburg, \& Cronburg (1969) made a comparison of voice and tone warnings used in conjunction with enunciator lights. The voice warning allowed the pilots the option of responding to, or ignoring the malfunction, depending on mission requirements and priorities. Importantly, voice warned pilot's reaction times were found to be faster than reaction times of tone warned pilots. These findings suggest that a voice message that can specifically describe the malfunction can reduce the pilot workload far more effectively and timely than a tone only warning system. A recognizable voice rapidly conveyed the information that a warning was being given, and the fact that the particular problem could be identified by the vocabulary of the warning message would suggest at least a probable course of action. One of the deficiencies of a voice message system is that it must use complete words and at least a rudimentary system of syntax. This involves defining the syntax system, developing the vocabulary, and storing the vocabulary in some sort of memory system, and then retrieving the stored phonemes and restructuring them into coherent messages. Simpson (1976) investigated the effects of message length and format on response times of commercial airline pilots. Warning messages were presented to the pilots as they were performing flight tasks in a simulator. These messages were of varying lengths and formats. The timing of the messages was such that they were presented during other simulated radio transmissions, such as weather reports. Messages using key words were compared to messages in full sentence format, for example "FUEL LOW" as opposed to "THE FUEL QUANTITY IS LOW". Results showed that the airline pilots displayed greater comprehension and faster response times when receiving the full sentence format. This finding must be weighed against the expected operating conditions of a commercial pilot versus that of a fighter-type aircraft pilot. The expected task loading of a fighter pilot is much higher than that of the commercial pilot. While comprehension was shown to be higher with the full sentence format, there may be insufficient time available to the fighter pilot to listen to the full sentence. The key word format may reduce the reaction time so that the timesaving will be significant. Simpson's finding notwithstanding, a study of British commercial airline pilots revealed that the preference was for the key word format (Wheale, 1980). This lends credibility to the pilot perception that the difference in comprehension levels between full sentence format and key word format is not as significant as the savings in reaction time experienced with using only key words. In a survey of American military fighter pilots, Folds (1985) discovered that when he asked for inputs for alternative wording to the voice message system vocabulary, "the alternate wordings suggested by the pilots in the present survey are, without exception, in key-word format" (p. 108). Thus, it appears that there is support in the user community for a shortened message length at the expense of comprehension. In this same survey, Folds highlights the differences between the voice warning systems of the newest fighters in the United States Air Force inventory, the F-15 and the F-16. The F-16 has a "WARNING, WARNING" message that accompanies 
warning lights, and a "CAUTION, CAUTION" message that accompanies the master caution light. The $F-15$ uses voice messages to inform the pilot of engine fire, accessory drive fire, fan turbine inlet temperature, low fuel, "Bingo" fuel, and over-g conditions (1985). These two voicewarning systems use quite different approaches to warning pilots. The F-16 message simply indicates the criticality level of the message and directs the pilot's attention to an enunciator panel, where the visual display contains the specific information of the malfunction. The F- 15 messages are far more specific and do not inherently réquire the pilot to look at the visual display, but they do not cover the wide range of conditions that are addressed by the more flexible F-16 system. In trying to identify a standardized vocabulary for voice warning systems, several obstacles are apparent. First, a standardized system would have difficulty in adequately reflecting the different systems on board, which would be required to be represented by the voice warning system. Second, a standardized vocabulary would be less able to take advantage of pilot jargon specific to a particular type fighter. Third, it would be necessary to disallow different approaches to the use of voice messages, even if those approaches are optimal for a particular type. That current aircraft use a female voice type for the recorded or synthesized voice is the result of an assumption made by early voice warning system designers. This assumption was that the female voice would stand out against the other voices in aviation radio transmissions which were predominantly male. This assumption was almost universally accepted without research support. Doll and Folds (1985) summarize the military specification for the initial voice type to be used on tactical fighter aircraft. "The voice used shall be distinctive and mature... in selecting the words to be used in the message, priority shall be given to intelligibility, aptness, and conciseness in that order" (p. 960). Wampler (1993) also cites the same specification. "The voice shall be distinctively female. It shall express the urgency required of the warning by its inflection" (p. A-6). Both these authors note that the only reason that a female voice was selected was the belief that the female voice would provide a contrast to the almost exclusively male population of fighter pilots, thereby standing out against tactical radio calls and conversation between front and back seat occupants. That this assumption was generally accepted without argument is edified in Wampler's (1993) report referenced earlier. In 1993, the U.S. Navy commissioned this report to study the voice warning requirements of a ground proximity warning system. A stated requirement in the design specifications was that the voice type must be fenale. Thus, the appropriateness of this voice type was not discussed. Most writers commenting on the selection of the female voice, for this reason, are quick to point out that the uniqueness of the female voice on the aviation airwaves is rapidly declining with the rise in numbers of female pilots commercially as well as militarily.

Several interesting studies have since shed light on the question of voice type. Backs and Walrath (1991) studied differences in mental workload required to process information from voice warning systems when different voice types were used. Specifically, they examined how speaker sex affected intelligibility, subjective confidence, and cardiovascular measures during performance of a standardized speech intelligibility test. The test used the Modified Rhyme Test and lasted for approximately five minutes, (Kryter, 1972). It consisted of six rhymes that varied according to either the start or the stop phoneme. The participants were required to rate how confident they were that their answer was correct. Results indicated a significant difference associated with speaker sex in all three categories studied. Intelligibility for female speakers was degraded by loss of high frequency context similar to what would be experienced in aircraft communications. Wind and engine noise found in all aircraft cockpits falls within this high frequency range (Kryter). This would indicate not only voice type considerations for voice warning systems, but implications for female pilots and controllers as well. Test subjects demonstrated increased confidence in the correctness of their answers when the speaker was male. That the confidence also varied with the background noise frequency suggests that the confidence level is directly related to inherent intelligibility. Results from the heart rate and heart range variability tests indicate that the participants experienced greater mental workload with female speakers than with male speakers. Backs and Walrath (1991) concluded that speaker sex did significantly impact intelligibility, confidence, and mental workload. Under actual flight conditions, the processing of auditory information is performed simultaneously with many other tasks under stress due to vibration and $\mathrm{g}$ forces, as well as noise. Thus, it is reasonable to expect that intelligibility would be lower and workload would be greater in flight and, that even the slightest changes to the system could prove to be operationally significant.

Freedman and Rambaugh (1983) found no consistent 
performance advantage with female voice types as opposed to male voice types. In fact, they make the strongest case against the female voice type when testing voice types for accuracy and speed. The results showed that higher speed was associated with the female voice types and higher accuracy with a male voice type. While the faster response time was associated with the female voice type, there are two mitigating factors: Response times were only calculated if the response was a correct response. The faster response time is dependent on the accuracy of the response, this being associated with the male voice type. Also, the warnings used during the test varied in length, with the female voice type warning being longer. When the length of the message is compensated for, the male voice type was associated with faster response times. In anticipation of questions, an analysis of response accuracy and speed was conducted based on subject sex. Subject sex was found significant for both accuracy and response time. The male subjects performed better in accuracy, while female subjects performed better in response time. Interestingly, the male subjects displayed no significant difference in accuracy between male or female voice types. The female subjects, however, had better accuracy when responding to the male voice, and a faster response time when responding to the female voice. Thus, the male voice was shown to result in more accurate responses, and the female voice shown to result in faster responses (unless message length is factored in), but only in the female subjects. This research concurs with that of Backs and Walrath (1991).

In addition to questionable alerting value, no consistent performance advantage has been found with female speakers. There may be no clear-cut advantage with regard to either alerting or information transmission.

While this is contrary to the accepted convention that the female voice type is preferable, it actually allows the designers and engineers to use the most practical and convenient voice type. Prior to the development of voice messaging systems which utilized the female voice type, little or no research had been done to determine what voice type would be most effective in commanding attention. By the time research was conducted, technology had progressed to the point that synthesized speech was now available, as opposed to the voice recordings used previously. An early hypothesis was that a clearly nonhuman synthesized voice would be an easily recognizable form amidst the noise clutter and voice transmissions.

Synthesized speech has been found to be sufficiently intelligible for use in airline cockpits for enunciation of warnings and advisories. Airline pilots have rated the intelligibility of such messages as equal to or greater than Air Traffic Control radio communications. Some pilots have noted that the distinctive quality of synthesized speech is an asset because it can easily be distinguished from other cockpit speech, and because they can tell immediately that a machine, rather than a human, is speaking (Simpson and Williams, 1980). It appears that synthesized speech can provide an adequate means of transferring information via voice warning systems. Research by Simpson, Frost, \& Navarro (1984) support this theory. Their study of helicopter pilots found that the pilots wanted a voice that would be distinctive in the background of male and female human voice radio transmissions, and that a machine quality voice would convey the warning of the message better than either a male or female human sounding voice. Some guidelines for desirable characteristics of voice types were suggested by the results. The voice ought to be distinctive, slightly mechanical sounding, and spoken at a rate of about $150 \mathrm{wpm}$. Also, listener's initial judgements of voice quality and preference may be expected to change with exposure to those voices in an operational environment. The study caveats the results in saying that the reason for the observed differences in results may be due to phonetic degradation during the speech encoding process. This impact is lessened due to advances in recording and encoding technologies.

While research and experience strongly support the use of verbal warning messages in aural warning systems, the use of the common human female voice is shown to have no greater impact than a human male-recorded voice. The preferred voice type is generally a synthesized voice easily distinguishable from human speech. This is due to the perception that the voice can indicate something about the identity of the speaker, in this case, a machine.

\section{Statement of Hypothesis}

It is hypothesized that a voice from a person in a position of authority over the pilot will be more effective at capturing the attention of fighter type aircraft aircrew than the current female voice type. The null hypothesis states that there will be no significant difference in the opinion of fighter type aircrew members as to whether a female voice or the voice of a person in a position of authority over the aircrew is more effective at capturing their attention. Significance is measured at the $a=.05$ level of significance. 


\section{Research Technique}

This study utilized the causal-comparative methodology to determine if there is a significant difference between the effectiveness of the voice of a person in a position of authority over the pilot, and the current female voice type when used in a voice message system.

The survey population was F-15, F-16, and A-10 aircrew from the $33^{\text {rd }}$ Wing, $53^{\text {rd }}$ Operational Test Wing, the $46^{\text {th }}$ Test Wing, all located at Eglin AFB, FL and the $347^{\text {th }}$ Wing, located at Tyndall AFB, FL. The data were gathered using a survey designed by the authors. It consisted of a series of questions to determine response group demographics, a series of questions to determine if the aircrew had experienced any missed advisories with the current voice message system voice type, and comparison questions to determine aircrew preferences in voice types. The survey was sent and replied too electronically. The researcher allowed two months for data gathering. A onedimensional Chi-Square test was used to analyze the relationship between the aircrew voice type comparisons. Support Questions

To establish a basis that external stimuli are ignored during high task situations, the respondents were asked if they had ever failed to respond to input via the aircraft radio. One hundred percent of the respondents indicated that they had failed to respond to a radio call because of high task saturation. The importance of this information is that it indicates that the problem of ignored aural inputs is universal (at least in the respondent group). It is the researcher's opinion that a similar $100 \%$ affirmative response would be found if all aircrew in all weapons systems were surveyed. What one cannot deduce from this is any indication of which voice type was responsible for these failures, nor can we draw any conclusions pertinent to the hypothesis. In order to establish that failures of recognition of the current female voice type occur, respondents were asked if they had ever failed to respond to a voice message system aural message.

Since all fighter aircraft flown by the respondents contain a similar voice type, that of a female, one can draw conclusions specific to this voice type. A majority of the respondents, $66 \%$, indicated that they had at least one instance of a failure to respond to the female voice type aural message. That two-thirds of the respondents would have experienced a failure suggests that there is substantial room of improvement in the effectiveness of the voice message, and lends credibility to the hypothesis.

In order for the voice of a person in a position of authority to be effective in capturing the attention of the aircrew, it must be recognizable as that person's voice. Aircrews were questioned to determine if they felt that the voices of their commanders were easily recognizable.

The results revealed that the respondents were evenly divided on the question of whether or not they felt the voice of a person in a position of authority would be more effective at capturing their attention during high task situations. Three voice types were compared, though each comparison was between only two voice types at one time. The third voice type compared was that of a computer synthesized voice, distinctly non-human. Though this does not impact directly on the hypothesis, after the review of pertinent literature the researchers believed that it was a valid comparison and might indicate a need for future research.

The first comparison, directly related to the hypothesis, compared the current female voice type and a recording of the voice of a person in a position of authority over the aircrew.

The results were contrary to the expected results and failed to support the hypothesis. The majority of respondents indicated that a recording of the voice of their commander was not more effective in capturing their attention. The Chi-Square test yielded a Chi-Square value of 16.00 , which exceeded the 3.841 value necessary for significance at $\mathrm{p}=.05$ with 1 degree of freedom (df) (Table 1). 
Table 1

Chi-square Results for Comparison of Female vs. Commander Voice Types

\begin{tabular}{|l|l|l|l|}
\hline \multicolumn{2}{|c|}{ Female Voice Preferred } & \multicolumn{2}{c|}{ Commander's Voice Preferred } \\
\hline Observed: & 60 & Observed: & 12 \\
\hline Expected: & 36 & Expected: & 36 \\
\hline
\end{tabular}

Chi-Square $=16.00$

$\mathrm{df}=1$

The next comparison takes on new importance considering the results of the first. Since it was found that aircrews prefer the female voice to the voice of a commander, possibly the computer synthesized voice, identified in pertinent literature, would be preferred over the female voice.

The results, however, did not support a hypothesis that the female voice would be less effective at capturing attention. The results indicated that the female voice is perceived to be more effective, by a significant number of aircrew, as compared to the computer-synthesized voice. The Chi-Square analysis is displayed in Table 2.

Again, a value of 3.841 is required for significance using an a-.05 level of significance with $1 \mathrm{df}$.

Table 2

Chi-Square Results for Comparison of Female vs. Computer Voice Types

\begin{tabular}{|l|l|l|l|}
\hline \multicolumn{2}{|c|}{ Female Voice Preferred } & \multicolumn{2}{c|}{ Computer Voice Preferred } \\
\hline Observed: & 64 & Observed: & 8 \\
\hline Expected: & 36 & Expected: & 36 \\
\hline
\end{tabular}

Chi-Square $=21.78$

$\mathrm{df}=1$ 
Table 3

Chi-Square Results for Comparison of Commander's Voice and Computer Voice

\begin{tabular}{|l|l|l|l|}
\hline \multicolumn{2}{|c|}{ Computer Voice Preferred } & \multicolumn{2}{c|}{ Commander's Voice Preferred } \\
\hline Observed: & 52 & Observed: & 20 \\
\hline Expected: & 36 & Expected: & 36 \\
\hline
\end{tabular}

Chi-Square $=7.11$

$\mathrm{df}=1$

Similar to the previous results, the results reinforce the aircrew preference for the current female voice type.

The final comparison of voice type was between a recording of the commander's voice and a computer synthesized voice. Aircrew members, by a significant margin, preferred the computer-synthesized voice to that of a recording of the voice of their commander. The ChiSquare analysis in Table 3 reveals that the aircrew preference is significant at the probability level of $a=05$. The data showed that aircrews do not prefer the recorded voice of a commander to that of the synthesized voice.

\section{Discussion}

All of the respondents reported missing radio calls during periods of high task loading. Over two-thirds of the respondents reported missing advisory voice messages. As noted in the discussion on test validity, the authors believe that this is a representative sample of the fighter aircrew community. The average experience level is quite high, with the majority of the hours having been flown in fighter type aircraft equipped with voice message systems. The number of aircrew who has actually missed an advisory voice message can be expected to be even higher, probably approaching the entire fighter aircrew community. This assumption is based upon the premise that while the question asks if an advisory voice message has ever been ignored, it does not ask if the message was ignored until after the high task situation. An advisory message will continue to repeat until the aircrew acknowledges the warning. This may be done inadvertently, or as a reflex action done without comprehending the data. In other words, the aircrew who responded that they never missed an advisory voice message may have responded to the message only after the high task situation had resolved to a lower task situation, or silenced the warning message without comprehending that the "noise" they were silencing was a warning. Either way, the fact that two-thirds of the respondents admit to having missed advisory voice messages indicated, at the very least, inefficiency and more appropriately, a cause for alarm within safety agencies.

In order for the research to be practical, the voice to be used in the recording must be recognizable to the aircrew. Only one-half of the respondents said that the voices of their commanders are recognizable. While this does not indicate that a voice message system utilizing this voice type would be initially effective, this recognition would be universal shortly after implementation. If this voice type was to be used, the aircrew would have knowledge that the voice was that of their commander. Thus, they would be able to recognize the voice as that of their commander after hearing it. This would occur during the system checks accomplished on the ground prior to flight. Most likely, aircrew would be exposed to it during simulator training, or as part of a training program when the voice type is changed. However, since recognition in this case would be learned, it might be said that this is exactly what is presently occurring with the current configuration. The aircrews are learning to recognize the female voice as the voice of the aircraft, and are attaching authority to that voice. This being the case, the voice type may not need to be recognizable to the aircrew initially, since it will be learned almost immediately. Since only one-half of the sample responded that the voices of their commanders are recognizable, a system, which relies on this factor, would not be beneficial over the current configuration. A system, which works for only one-half of the aircrew, is not adequate. This point is borne out by the results of the voice type comparisons.

As the data in Table 1 demonstrated, the Chi-Square analysis revealed a significant proportion of respondents preferred the current female voice type. This data does not 
support the research hypothesis. Given that only half of the respondents felt that they could easily recognize their commander's voices, this is not surprising. As mentioned earlier, the recognition of the voice type would be learned in either case. If the voice were changed with every change of commander, a new voice would have to be learned at the same interval. This would equate to added work, and risk, and would not equal a net gain in effectiveness.

This being the case, and in light of previous research indicating a female voice type may not be the optimal, or at least an arbitrary choice, a comparison between the female voice type and a computer synthesized voice would be suggested. The respondents, however, preferred the female voice to that of the computer in even greater proportion than over the recorded voice of the commander (Table 2). The reasons for this are unclear. Possibly inertia is the greatest culprit, along with a certain machismo. The female voice type is what aircrew is used to and a new voice type would be a change to what they are accustomed. Also, all of the respondents were male. Each was introduced to fighter flying at a time when only males were eligible for combat billets, and the universally accepted voice type was female. To say that they preferred to hear any voice type other than a female may have never occurred to them, and may have seemed incompatible to this traditional male domain.

As demonstrated by Table 3, a significant proportion preferred the synthesized voice to that of the commander. This point is in keeping with previous research, which indicates a clearly non-human voice should be more effective at capturing attention.

\section{Conclusions}

Analysis of the data does not support the research hypothesis. To the contrary, data suggests a strong affinity for the current configuration. The authors speculate that this could be explained by several assumptions, primarily inertia and machismo. A measure of inertia is expected to some degree and is supported by the significant proportion preferring the female voice to the synthesized voice as well. To some extent, this is a valid reason. This paper does not attempt to determine whether or not the current configuration of voice message systems is effective, or even what level of effectiveness is a requirement. Apparently, the operators of the weapons systems believe the fielded voice message systems do an adequate job because no great outcry has been heard to change them. This being the case, changing from one adequate system to another adequate system introduces an element of risk where little or none had existed before. This may or may not be the case. Previous research is in opposition to studies that favor the use of a synthesized voice. To some extent, the data from the comparison between the computer voice and the recording of the commander support this theory. Inertia is not a factor in this comparison, and the synthesized voice is preferred in a significant proportion. This appears to be the only line of future research suggested by the data.

\section{Recommendations}

Additional research should be conducted to confirm these findings, thereby ruling out the recorded voice of a person in a position of authority over the aircrew as a promising alternative to the current voice configuration. Since only one-half of the pilots surveyed stated that they would be able to recognize their commander's voice, a limitation of this study, future research should address this concern by ensuring that the survey participants are familiar with the voices of their commanders before taking part in the study.

While the pursuit of a more effective voice type is valid, it may not provide benefits that justify the expense. The operator, in this case, the United States Air Force, must dictate this requirement. However, with several new fighter weapons systems in development, optimization of each component should be considered.

For future fighter weapons systems optimization, additional research should be conducted evaluate effectiveness of a synthesized voice type over the female voice type. If a voice could be synthesized in such a way as to be clearly non-human yet female, the findings may justify implementation of voice configurations utilizing a synthesized female voice type. $\square$ 
Gary Bell holds a Masters of Aeronautical Science degree from Embry-Riddle Aeronautical University. Major Bell is an officer in the United States Air Force holding a senior pilot rating. He is currently Chief, F-16 Standardization and Evaluation for the $46^{\text {th }}$ Operations Group, $46^{\text {th }}$ Test Wing, Eglin AFB, Florida. He has accumulated over 1,500 hours of flight time in the F-16, of which approximately 750 hours is instructor time and 50 hours as a Stan Eval Flight Examiner. He also has 274 hours of combat flight time.

James T. Schultz holds a Bachelor's degree from Michigan State University, a Master's degree from the University of Oklahoma, and a Doctorate from the University of Southern California. He is an Associate Professor of Aviation Business Administration at Embry-Riddle Aeronautical University and is retired from the U.S. Air Force.

Marian C. Schultz holds both Associate's and Bachelor's degrees from the University of Detroit Mercy, a Master's degree from Pepperdine University, and a Doctorate from the University of Southern California. She is a tenured Associate Professor at The University of West Florida. 


\section{REFERENCES}

Backs, R.W., \& Walrath, L. C., (1991). Heart Rate Variability and Auditory Workload During Noise Stress: Speaker Sex and Bandpass Effects on Speech Intelligibility. Proceedings of the Sixth International Symposium on Aviation Psychology, VOL. 2. Ohio State University Department of Aviation, Columbus, Ohio, 740-745

Doll, T. J., \& Folds, D., (1985). Auditory signals in military aircraft: Ergonomic principles versus practice. Proceedings of the IEEE 1985 National Aerospace and Electronics Conference, pp. 958-965

Edworthy, J., \& Stanton, N. (1995). A user-centered approach to the design and evaluation of auditory warning signals: 1. Methodology. Ergonomics, VOL. 38, NO. 11, 2262-2280.

Folds, D. J., (1985). Development of a comprehensive voice message vocabulary for tactical aircraft. Proceedings of the Third Symposium on Aviation Psychology Ohio State University Department of Aviation, Columbus, Ohio, 103-110.

Freedman, J., \& Rumbaugh, W. A., (1983). Accuracy and Speed of Response to Different Voice Types in a Cockpit Voice Warning System. Master's Thesis presented to School of Systems and Logistics, Air Force Base, Ohio.

Kemmerling, P., Geiselhart, R, Thorburg, D. E., \& Cronburg, J. G. (1969, September). A comparison of voice and tone warning systems as a function of task loading. Aeronautical Systems Division, Wright-Patterson Air Force Base, Ohio, Technical Report ASD-TR-69-104.

Kryter, K. D., (1972). Speech Communication. Human Engineering Guide to Equipment Design. Washington, DC, Department of Defense

Simpson, C. A., (1976). Effects of linguistic redundancy on pilot's comprehension of synthesized speech. Proceedings of the Twelfth Annual Conference on Manual Control. NASA Technical Report TMX-73170

Simpson, C. A., \& Williams D. H., (1980) Response Time Effect of Alerting Tone and Semantic Context for Synthesized voice Cockpit Warnings. Human Factors, 22(3), 319-330

Simpson, C. A., Marchionda-Frost, K., \& Navarro, T., (1984). Comparison of Voice Types for Helicopter Voice Warning Systems. Third Aerospace Behavioral Engineering Technology Conference Proceedings "Automation Workload Technology: Friend or Foe?" 217-224.

Wampler, D., (1993). Ground Proximity Warning System Voice Warning Unit Requirement Study. Naval Air Warfare Center, Indianapolis, Indiana, Performer Organization Report Number TR-2481

Wheale, J., (1980). Pilot opinion of flight deck warning systems. Human Factors in Transport Research VOL. 1, 88-96 


\section{APPENDIX}

\section{DATA GATHERING INSTRUMENT}

\section{AIRCREW QUESTIONNAIRE}

1. Aircrew Background:

\section{Rating}

Current Aircraft Type

Highest Qualification

Flight Hours in Type

Total Flight Time

2. Have you ever missed a radio call due to task saturation?

3. Have you ever missed an advisory voice message due to task saturation?

4. Are the voices of your Squadron, Group and Wing Commanders easily recognizable to you?

5. Currently the voice messaging system uses the voice pattern of a generic female. Consider that a recording of the voice of one of your commanders could be used in place of the generic female voice. Also, consider that a computer-generated voice, synthesized so that it is clearly not human could be used. Which of these voices do you feel would be more effective in capturing your attention in a high task situation?

6. Below are comparisons of the three voice patterns. Place an $X$ beside the voice you feel would be more effective in capturing your attention in a high task situation.

a. Current Female Voice--

Recording of Commander-..

b. Current Female Voice---

Computer Synthesized Voice---

c. Recording of Commander-

Computer Synthesized Voice-- 
Journal of Aviation/Aerospace Education \& Research, Vol. 10, No. 1 [2000], Art. 9 